\title{
Ultrasound biomicroscopy in the management of melanocytoma of the ciliary body with extrascleral extension
}

\author{
M D Mohamed, M Gupta, A Parsons, I G Rennie
}

Br J Ophthalmol 2005;89:14-16. doi: 10.1136/bjo.2004.048967

\begin{abstract}
Aim: To demonstrate the ultrasound biomicroscopic features of a ciliary body melanocytoma with extrascleral extension, and a conservative approach in its management.

Method: Observational case reports. Two cases of ciliary body melanocytoma were suspected at presentation, confirmed histologically by biopsy, and subsequently monitored for change by serial ultrasound biomicroscopic imaging. The main outcome measures were anatomical and functional preservation of the eye, with avoidance of formal surgical excision.

Results: Ultrasound biomicroscopy allows clear visualisation of the tumours, and the ultrasound characteristic is of low homogeneous internal reflectivity. 5 year follow up with observation only demonstrates success with this conservative management approach. Histopathological evaluation confirmed melanocytoma.

Conclusions: Melanocytoma is a rare tumour. However if considered in the differential diagnosis at presentation and confirmed histologically, further management with use of the ultrasound biomicroscope as an accurate mode of imaging is an acceptable technique for preservation of the eye and avoids surgical excision.
\end{abstract}

M elanocytoma ${ }^{1}$ (magnocellular naevus ${ }^{2}$ ) is an uncommon tumour ${ }^{3}$ of the uveal tract which is generally regarded as benign, having the ability for invasion of local tissues, ${ }^{4}$ but has never been shown to metastasise. ${ }^{5}$ Classically it is described at the optic nerve head, ${ }^{1}$ but it is encountered less frequently at the ciliary body ${ }^{6}$ and there are rare reports of occurrence in the iris, ${ }^{7}$ sclera, ${ }^{8}$ conjunctiva, ${ }^{9}$ and choroid. ${ }^{10}{ }^{11}$

Despite diagnostic accuracy being high in ocular melanotic lesions, ${ }^{12}$ in previous reports the diagnosis of melanocytoma has been made subsequent to surgical intervention where the tumour has been thought to be malignant melanoma. ${ }^{13}{ }^{14}$ Here we report two cases where the diagnosis of melanocytoma of the ciliary body with extrascleral extension was suspected at presentation and confirmed histologically with a biopsy of the extraocular tumour extension. ${ }^{15}$

Ultrasound biomicroscopy is a particularly valuable technique for high resolution evaluation of anterior segment tumours in vivo. ${ }^{16}$ The aim of this report is to exhibit ultrasound biomicroscopic images and features of this tumour, and demonstrate a novel conservative approach to its management by serial ultrasound biomicroscopic imaging.

\section{PATIENTS AND METHODS \\ Case 1}

A 57 year old white man was referred to the ocular oncology service for evaluation of an asymptomatic pigmented lesion on the superior aspect of his left sclera, present for 10 years, and associated with a ciliary body mass.

On examination his visual acuity was $20 / 15$ bilaterally, and an area of jet black pigmentation was present at the $1 o^{\prime}$ clock position on his sclera around an emissary vein. Gonioscopy showed pigmentation in the adjacent drainage angle, but no pigment dispersion, and a normal intraocular pressure (16 mm $\mathrm{Hg}$ ). A small pigmented tumour was visible arising from the ciliary body.

Ultrasound biomicroscopy was performed, which showed a solid ciliary body tumour with low internal reflectivity and a small anterior cystic element (fig lA). The remainder of the ocular examination was unremarkable.

In view of the long history of the intensely pigmented episcleral lesion, melanocytoma was suspected and a biopsy was performed.

\section{Pathological findings}

Macroscopically a piece of deeply pigmented tissue $3.0 \mathrm{~mm} \times 2.0 \mathrm{~mm}$ was examined. Microscopically this consisted of plump polyhedral or round heavily pigmented cells with abundant cytoplasm in which nuclear detail was mostly obscured by granular melanosomes (fig lC). Bleached preparations show round and ovoid nuclei with no nucleoli in the majority of cells (fig 1D). The features are consistent with the diagnosis of melanocytoma; this was confirmed by two independent ocular pathologists.

Follow up

At 5 year follow up, this patient continues to maintain normal visual acuity, and serial ultrasound biomicroscopic imaging has failed to show extension of the lesion (fig $1 \mathrm{~B}$ ).

\section{Case 2}

A 77 year old white man was referred with a pigmented lesion on the superonasal aspect of his right sclera.

On examination his visual acuity was 20/30 bilaterally, and an area of deep pigmentation was noted at the 1 o'clock position close to the limbus. Gonioscopy showed increased local drainage angle pigmentation, no pigment dispersion, and normal intraocular pressure. No obvious ciliary body mass was noted. The remainder of the ocular examination was normal.

Ultrasound biomicroscopy revealed a ciliary body mass underlying the episcleral pigmentation, and it also had a homogeneous appearance with low internal reflectivity, measuring $4.0 \mathrm{~mm} \times 1.7 \mathrm{~mm}$.

\section{Pathological findings}

Macroscopic examination shows a piece of darkly pigmented tissue, measuring $2.0 \mathrm{~mm} \times 1.0 \mathrm{~mm}$, which microscopically is composed of highly pigmented plump polyhedral cells. The nuclei are mostly obscured by granular melanosomes, which 


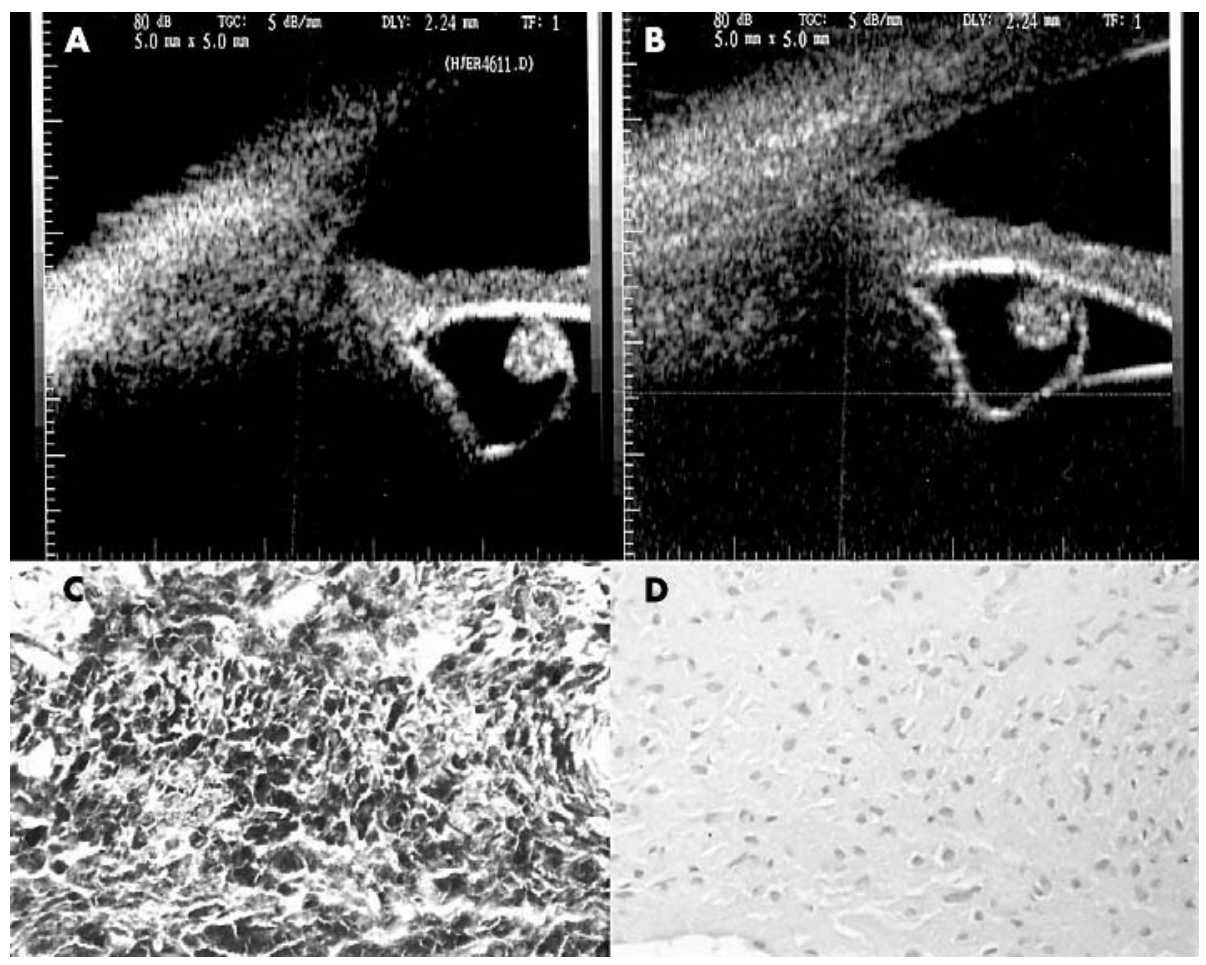

Figure 1 (A) Preoperative ultrasound biomicroscopy of the lesion showing a ciliary body tumour with low internal reflectivity and anterior cystic element. (B) Ultrasound biomicroscopy 3 years after biopsy showing no change in the appearance of the melanocytoma. (C) Histology (haematoxylin and eosin, $\times 800$ ). Melanocytes packed with melanosomes mostly obstructing nuclei. (D) Melanin bleach preparation $(\times 800)$ showing tumour cells have round or oval nuclei without nucleoli. on bleached preparations show small round and ovoid nuclei with no nucleoli. Some non-pigmented cells with elongated nuclei were seen in adjacent tissue. No neoplastic features were seen. The appearances are consistent with melanocytoma; this was also confirmed by two independent ocular pathologists.

\section{Follow up}

Similarly, at 5 year follow up, there is no deterioration in visual acuity, or change in appearance of the lesion on successive ultrasound biomicroscopy.

\section{DISCUSSION}

This report demonstrates ultrasound biomicroscopic images of a ciliary body melanocytoma and the ultrasound image characteristics as observed by this relatively new imaging technique. Also, we have shown that careful monitoring with this instrument allows a novel conservative management approach.

In both of these cases, histopathological study confirmed melanocytoma. The appearances are consistent with "type 1 " cells accounting for the majority of the cellular population, and it is likely that the infrequently encountered elongated cells are "type 2 " cells. ${ }^{17}$ The cytological features of type 1 cells are consistent with a metabolically inactive and benign cell, which correlates well with the pigmentation and lack of growth seen in these cases. Type 2 cells are the metabolically active subtype whose cytological features are believed to account for the propensity towards growth and invasion, and their presence in the extrascleral portion, the advancing edge of this tumour, is compatible with this theory.

We appreciate that false negative errors can be associated with biopsy, by sampling a benign area within a tumour and avoiding the area of aggressive growth. Further reliability and confidence in the biopsy could have been afforded by additional fine needle aspiration of the main tumour within the ciliary body, which is regarded as a safe and accurate method for sampling intraocular lesions. ${ }^{15}$
The differential diagnosis of a ciliary body pigmented mass is not too exhaustive. The major diagnostic challenge presented is distinguishing between malignant melanoma, carcinoma, and adenocarcinoma of the pigmented ciliary epithelium. Medulloepithelioma, a congenital tumour, and hyperplasia of the pigmented ciliary epithelium, usually secondary to trauma or surgery, can usually be eliminated by the history.

Ultrasound biomicroscopy is an invaluable tool in the management of such lesions. Precise visualisation and measurement allows accurate objective definition of tumour extent, its interface with surrounding anatomy, and internal features. ${ }^{16}$ Correlation of tumour characteristics with histological features is good, and ultrasound biomicroscopic images can have resolving power up to $50 \mu \mathrm{m}$, which is analogous to low power light microscopy. A malignant melanoma of the ciliary body also has low internal reflectivity but is more vascular than melanocytoma. Also from features of internal reflectivity, inferences can be drawn about the cellular structure. The low internal reflectivity seen here implies a cohesive internal cytoarchitecture, with lack of vascularity. $^{18}$

There are two characteristics of clinical importance, which were not encountered here, with whose development we would be particularly concerned. Necrosis, which was seen in 10 of 23 cases in one series, ${ }^{13}$ and can result in pigment dispersion and secondary glaucoma, ${ }^{19}{ }^{20}$ and malignant transformation, which is fortunately an infrequently encountered phenomenon. ${ }^{21}$

In view of the essentially benign nature of this lesion, the conservative management approach described above was tested once the initial diagnosis was made based on biopsy. From our observations we conclude this approach is safe with regular follow up, in order to detect any alteration in the character of the tumour, or secondary complications. If such progression is noted, we would advocate formal en bloc surgical excision as a potentially curative management option. $^{22}$ 


\section{Authors' affiliations}

M D Mohamed, Department of Ophthalmology, Chancellor's Wing, St James's University Hospital, Beckett Street, Leeds LS9 TTF, UK M Gupta, I G Rennie, Department of Ophthalmology, Royal Hallamshire Hospital, Glossop Road, Sheffield S10 2JF, UK

A Parsons, Department of Histopathology, Royal Hallamshire Hospital, Glossop Road, Sheffield S10 2JF, UK

Correspondence to: Mr Mohit Gupta, Department of Ophthalmology, Royal Hallamshire Hospital, Glossop Road, Sheffield S10 2JF, UK; mohiteye@yahoo.co.uk

Accepted for publication 7 June 2004

\section{REFERENCES}

1 Zimmerman LE, Garron LK. Melanocytoma of the optic disc. Int Ophthalmol Clin 1962;2:431-40.

2 Cogan D. Pigmented ocular tumours. In: Boniuk M, eds. Ocular and adnexal tumours; new and controversial aspects. St Louis: CV Mosby, 1964:385.

3 Howard GM, Forrest AW. Incidence and location of melanocytomas. Arch Ophthalmol 1967;77:61-6.

4 Zimmerman LE. Melanocytes, melanocytic nevi and melanocytomas. Invest Ophthalmol 1965;4:11-41.

5 Raichand M. Peyman GA, Juarez CP, et al. Resection of uveal melanocyłoma: clinicopathological correlation. Br J Ophthalmol 1983;67:236-43.

6 Shammas HJ, Minckler DS, Hulquist R, et al. Melanocytoma of the ciliary body. Ann Ophthalmol 1981;13:1381-3.

7 Shields JA, Augsburger JJ, Bernardino V Jr, et al. Melanocytoma of the ciliary body and iris. Am J Ophthalmol 1980:89:632-5.

8 Lee JS, Smith RE, Minckler DS. Scleral melanocytoma. Ophthalmology 1982;89:178-82.
9 Verdaguer J, Valenzuela H, Strozzi L. Melanocyłoma of the conjunctiva. Arch Ophthalmol' 1974;91:363-6.

10 Shields JA, Font RL. Melanocytoma of the choroid clinically simulating a malignant melanoma. Arch Ophthalmol 1972;87:396-400.

11 Jurgens I, Roca G, Sedo S, et al. Presumed melanocytoma of the macula. Arch Ophthalmol 1994;112:305-6.

12 COMS Report No 1 . Accuracy of diagnosis of choroidal melanomas in the Collaborative Ocular Melanoma Study. Arch Ophthalmol 1990;108:1268-73.

13 Frangieh GT, el Baba F, Traboulsi El, et al. Melanocytoma of the ciliary body: presentation of four cases and review of nineteen reports. Surv Ophthalmol 1985:29:328-34

14 Biswas J, D'Souza C, Shanmugam MP. A diffuse melanotic lesion of the iris as a presenting feature of ciliary body melanocytoma: report of a case and review of the literature. Surv Ophthalmol 1998;42:378-82.

15 Char DH, Miller TR, Crawford JB. Cyłopathologic diagnosis of benign lesions simulating choroidal melanomas. Am J Ophthalmol 1991:112:70-5.

16 Pavlin CJ, McWhae JA, McGowan HD, et al. Ultrasound biomicroscopy of anterior segment tumors. Ophthalmology 1992;99:1220-8.

17 Juarez CP, Tso MO. An ultrastructural study of melanocytomas (magnocellular nevi) of the optic disk and uvea. Am J Ophthalmol 1980:90:48-62.

18 Maberly DA, Pavlin CJ, McGowan HD, et al. Ultrasound biomicroscopic imaging of the anterior aspect of peripheral choroidal melanomas. Am J Ophthalmol 1997;123:506-14.

19 Bhorade AM, Edward DP, Goldstein DA. Ciliary body melanocytoma with anterior segment pigment dispersion and elevated intraocular pressure. $J$ Glaucoma 1999;8:129-33.

20 Shields JA, Annesley WH Jr, Spaeth GL. Necrotic melanocytoma of iris with secondary glaucoma. Am J Ophthalmol 1977:84:826-9.

21 Roth AM. Malignant change in melanocytomas of the uveal tract. Surv Ophthalmol 1978;22:404-12.

22 Rummelt V, Naumann GO, Folberg R, et al. Surgical management of melanocytoma of the ciliary body with extrascleral extension. Am J Ophthalmol 1994;117:169-76. 